\title{
Erratum to: The use of technology platforms as a policy tool to address research challenges and technology transfer
}

\author{
Liliana Proskuryakova ${ }^{1} \cdot$ Dirk Meissner $^{1} \cdot$ \\ Pavel Rudnik ${ }^{2}$
}

Published online: 23 June 2015

(C) Springer Science+Business Media New York 2015

\section{Erratum to: J Technol Transf DOI 10.1007/s10961-014-9373-8}

The original version of this article unfortunately contained a mistake. The acknowledgments section was missing. It is now given below. The authors apologise for this error and the inconvenience it has caused.

Acknowledgments The article was prepared within the framework of the Basic Research Program at the National Research University Higher School of Economics (HSE) and supported within the framework of the subsidy granted to the HSE by the Government of the Russian Federation for the implementation of the Global Competitiveness Program.

The online version of the original article can be found under doi:10.1007/s10961-014-9373-8.

Liliana Proskuryakova

lproskuryakova@hse.ru

Dirk Meissner

dmeissner@hse.ru

Pavel Rudnik

rudnikpb@mos.ru

1 Research Laboratory for Science and Technology Studies, National Research University "Higher School of Economics", Myasnitskaya Street, 20, Office 501, 101000 Moscow, Russia

2 Present Address: Russian Ministry for Economic Development, 1st Tverskaya-Yamskaya Street, 1-3, 125993 Moscow, Russia 